\title{
A Evolução Recente do Rendimento Escolar das Crianças Brasileiras: uma reavaliação dos dados do Saeb
}

\author{
REYNALDO FERNANDES \\ Professor do Departamento de Economia, FEARP-USP \\ refernan@usp.br \\ PAULO ESTEBAN NATENZON \\ Professor do Departamento de Economia, FEARP-USP \\ paulo@fearp.usp.br
}

\begin{abstract}
Resumo
O presente trabalho analisa a queda no desempenho escolar das crianças brasileiras observada no Saeb (1995-1999). Avalia-se a hipótese de que esse pior desempenho esteja associado à mudança do perfil das crianças avaliadas, em virtude da redução nas taxas de repetência e evasão escolar, também observadas no período. $\mathrm{O}$ argumento defendido no presente artigo é que a forma mais apropriada para avaliar mudanças na qualidade das oportunidades educacionais oferecidas pelo sistema seria comparar diferentes gerações, ao invés de comparar o desempenho de determinadas séries em anos distintos. Quando esse procedimento é realizado, observa-se que o desempenho escolar vem melhorando entre gerações sucessivas.

Palavras-chave: atraso escolar, evasão escolar, desempenho escolar, Saeb, TRI.
\end{abstract}

\section{Resúmen}

Este trabajo analiza el declinio del desempeño escolar de niños brasileros en Saeb (19951999). Se evalua la hipótesis de que ese peor desempeño esté asociado a la alteración del perfil de los niños evaluados, por la reducción de las tasas de repetentes y evasión escolar, también observadas durante ese periodo. El argumento defendido en el presente artículo es que la forma más apropiada para evaluar los cambios en la calidad de las oportunidades educativas ofrecidas por el sistema, sería comparar a diferentes generaciones, y no tanto la comparación del desempeño de determinados grados en años distintos. Cuando se sigue ese proceso, se observa que el desempeño escolar va mejorando en las generaciones sucesivas. Palabras-clave: atraso escolar, evasión escolar, desempeño escolar, Saeb, TRI.

\begin{abstract}
This paper investigates the reduction of Brazilian students' educational performance as shown in Saeb (1995-1999). We consider the hypothesis that the decline in the performance shown in the sample is due to changes in the characteristics of the evaluated students. This could be explained by a decrease in dropout and repetition rates observed during that period. Furthermore, the paper argues that the most appropriate way to evaluate the quality
\end{abstract}


of educational services offered by any educational system is to compare different generations instead of comparing students' performances in the same grades but in different years. When this procedure is carried out, we observe an improvement in educational performance between generations.

Key words: student repetition, student dropout, educational performance, IRT, Saeb. 


\section{INTRODUÇÃO}

As estatísticas disponíveis indicam que, na década de 90, o Brasil apresentou uma melhoria significativa nos indicadores de cobertura e fluxo escolar. Tais indicadores mostram que nossas crianças estão permanecendo mais tempo na escola e nela estão menos sujeitas a "tropeços" (repetências) do que nas duas décadas anteriores. Por exemplo, os dados da PNAD mostram que a escolaridade média das crianças brasileiras de 10 (14) anos de idade era 1,32 (3,54) anos completos de estudo em 1982, $1,75(4,13)$ em 1992 e 2,24 (4,99) em 19991.

No final da década de 1980 e início da década de 1990, a tese de que as altas taxas de repetência, principalmente nas primeiras séries do ensino fundamental, constituíam-se no principal entrave do sistema educacional brasileiro, ganhou força entre os especialistas em educação². Os possíveis motivos para as elevadas taxas de retenção foram, e ainda são, extremamente discutidos na literatura ${ }^{3}$. Com base nesse diagnóstico, uma série de intervenções públicas (nas diversas esferas de governo) vem sendo defendida e implementada no sistema público de ensino. Tais intervenções parecem estar sustentadas em dois princípios básicos: a) o ensino fundamental deve ser considerado prioritário; b) é necessário que se adotem medidas para combater a repetência.

Iniciativas do governo federal como o Fundo de Manutenção e Desenvolvimento do Ensino Fundamental e Valorização do Magistério (Fundef) e o Programa Nacional de Garantia de Renda Mínima, bem como a implementação/expansão de classes de aceleração e programas de progressão continuada (promoção automática) em diversas redes do ensino público estadual e municipal são exemplos de medidas que buscam atender a tais princípios. A avaliação dos resultados específicos das recentes intervenções no sistema público de ensino é ainda uma agenda em aberto e está além dos objetivos do presente trabalho. De qualquer modo, parece não ser muito controverso considerar que tais intervenções, tomadas no seu conjunto, foram importantes para a melhora dos

\footnotetext{
1 Este mesmo quadro pode ser diagnosticado pelas estatísticas de matrículas e taxas de promoção no ensino básico (Ministério da Educação, 2001).

2 Para isso, os trabalhos questionando as estatísticas oficiais acerca da retenção e evasão foram de fundamental importância. Esses trabalhos apontavam que as elevadas taxas de evasão apresentadas nas estatísticas oficiais estavam erradas: as taxas de evasão nas primeiras séries do ensino fundamental eram baixas, o grau de cobertura era elevado, enquanto que as taxas de repetência eram demasiadamente elevadas (Fletcher, Ribeiro 1987; Castro, Fletcher,1993; Ribeiro 1991).

3 Ver, por exemplo, Brandão, Baeta, Rocha, 1983; Ribeiro, 1991; Silva, Davis, 1993; Schiefelbein, Wolff, 1993; Paro, 2000.
} 
indicadores de cobertura e fluxo escolar. A discussão é bem mais controversa quando o assunto se refere ao impacto de tais medidas acerca da qualidade de ensino. Aqui, especial atenção deve ser dada aos programas de progressão continuada, pois são aqueles que dão margem a um debate mais acalorado 4 .

Enquanto governos e pesquisadores favoráveis às medidas adotadas apresentam a melhoria nos indicadores de cobertura e fluxo escolar como evidência da correção das políticas implementadas, a posição crítica poderia ser resumida da seguinte forma: não adianta manter as crianças na escola por mais tempo se na escola elas aprendem menos! Muitos críticos vêem, por exemplo, a promoção automática como um subterfúgio para encobrir as mazelas que ocorrem no interior das escolas, seria como quebrar o termômetro para não diagnosticar a febre.

A posição crítica ganhou força com a divulgação do Sistema Nacional de Avaliação do Ensino Básico (Saeb) 5 no ano de 1999, onde os resultados se mostraram inferiores aos obtidos no Saeb-1995. Por exemplo, nos atendo aos alunos da $4^{\text {a }}$ série do ensino fundamental, a pontuação média em matemática em 1999 foi 5,1\% inferior à obtida em 1995, enquanto que a pontuação média em língua portuguesa foi 9,3\% menor. A explicação do Ministério da Educação e de alguns secretários da educação dos estados é que essa queda se justificaria pela expansão das matrículas, que trouxe um perfil de aluno mais carente e menos preparado para o sistema de ensino. Assim, a queda na pontuação média dos alunos não poderia ser entendida como um sinal negativo. As reações negativas a essa explicação foram inúmeras ${ }^{6}$. O fato, no entanto, é que o discurso oficial não é desprovido de sentido.

Pelo menos desde o Relatório Coleman (Coleman, 1966), sabe-se o quão importante são as variáveis socioeconômicas na determinação do desempenho escolar (pontuação em exames padronizados) das crianças. Assim, se o perfil socioeconômico e as características pessoais das crianças que, por exemplo, freqüentam a $4^{\text {a }}$ série do ensino fundamental vêm se

4 Para uma discussão em relação às virtudes e riscos da progressão continuada, ver, entre outros, Silva, Davis, 1993; Demo, 1998; Mainardes, 1998; Neubauer, 2000.

5 O Saeb é um instrumento de avaliação da educação básica, implantado em 1990 pelo Instituto Nacional de Estudos e Pesquisas Educacionais (Inep). O levantamento de dados no Saeb é bienal e constituído por provas de várias disciplinas e questionários contextuais, que permitem obter características da escola, do diretor, do professor, da turma e dos alunos que participam da avaliação. Para mais informações acerca do Saeb consultar, por exemplo, Ministério da Educação, 1999.

6 Por exemplo, o jornal O Dia $(27 / 11 / 2000)$, em editorial, afirmava: “É uma avaliação reducionista e preconceituosa. Faz parecer que a culpa é dos estudantes pobres.... Chega de cantar vitórias alardeando número de matrículas e redução na evasão escolar. O que adianta multiplicar os números em sala de aula, se o ensino é ruim?" 
alterando ao longo dos anos, uma diferença na pontuação média entre dois anos distintos não pode ser atribuída automaticamente a uma mudança na qualidade dos serviços oferecidos pelo sistema educacional. Em outras palavras, diferenças nos resultados obtidos nos Saebs de 1995 e 1999 podem refletir tanto mudanças do perfil dos alunos avaliados como mudanças das oportunidades que o sistema de ensino oferece: qualidade das escolas e/ou a existência de outros serviços que facilitam o aprendizado dos alunos (bolsa-escola, transporte escolar, etc.).

Cabe ressaltar que a redução de desempenho escolar em períodos de expansão de matrículas não é um fenômeno que ocorreu apenas no Brasil. Por exemplo, Hanushek (1986) mostra que nos Estados Unidos a pontuação média do SAT (Scholastic Aptitude Test), realizado para os graduados do segundo grau (high school), apresentou uma forte redução entre 1960 e 1980, período de forte crescimento na parcela de pessoas que, na idade correta, se matricula na high school. Entre 1963 e 1980 a pontuação média para os teste de expressão verbal caiu cerca de meio desvio padrão da distribuição de pontos da população avaliada em 19797 , enquanto que para a população entre 25 e 29 anos de idade a proporção de pessoas com pelo menos 4 anos de high school foi de 60,7\% em 1960 para 84,5\% em $1980^{8}$. Mais interessante é que a queda na pontuação média dos testes ocorreu em um período onde os recursos por aluno se elevaram significativamente. Os gastos correntes anuais por aluno (ensino público elementar e secundário) se elevaram (em dólares de 1983) de US\$ 1.262 em 1960 para US\$ 2.960 em $1983^{9}$.

$\mathrm{O}$ argumento defendido no presente artigo é que a forma mais apropriada para avaliar mudanças na qualidade das oportunidades educacionais oferecidas pelo sistema seria comparar diferentes gerações, ao invés de comparar o desempenho de determinadas séries em anos distintos. Assim, as crianças de uma determinada geração seriam avaliadas

\footnotetext{
7 Para matemática essa queda foi menor, pouco acima de 0,2 desvio padrão. A queda verificada no teste de expressão verbal significa que a pontuação média de 1979 equivale à pontuação do aluno situado no $32^{\circ}$ centésimo da distribuição de pontos em 1963.

8 Em termos absolutos o número de matriculas se reduz a partir de 1975 para a high school e a partir de 1970 para a escola elementar. A queda do número absoluto de matrículas, relacionada com o aumento da parcela de matriculados de uma geração, está associada à redução do tamanho das coortes, em função da passagem da geração do baby boom pelo sistema escolar.

9 Grande parte deste aumento de gastos está associado à redução da relação alunoprofessor. Essa relação se reduziu, entre 1960 e 1980, de 25,8 para 19,0. Considerando apenas o ensino secundário a relação aluno-professor foi de 21,7 para 17,1 . Novamente, essa redução pode, pelo menos em parte, ser explicada pela passagem da geração do baby boom pelo sistema escolar. Isto porque a redução no número total de matrículas não foi acompanha pela redução do número de professores.
} 
em diferentes idades, independentemente da série que estão cursando. Isso nos possibilitaria comparar crianças de diferentes gerações na mesma idade (10 anos em 1995 e 10 anos em 1999, por exemplo) e, deste modo, avaliar como o desempenho dos alunos tem variado entre gerações. Note que, nesse caso, a correção do fluxo escolar só interferiria na pontuação média (mediana, ou qualquer outra posição na distribuição de habilidades) ${ }^{10}$ de uma determinada geração à medida que tal correção estivesse associada a mudanças nos conhecimentos e habilidades adquiridos, e não por alterar a parcela de crianças que é avaliada.

Evidentemente, o perfil socioeconômico não é fixo entre gerações ${ }^{11}$. Entretanto, essas mudanças tendem a ser lentas e, deste modo, tendem a ser pouco perceptíveis entre gerações próximas (4 anos de diferença no caso em questão). Assim, diferenças significativas nas pontuações (média, mediana, ou qualquer outra medida de posição na distribuição) de exames padronizados entre duas gerações próximas seriam, em grande medida, causadas por mudanças na qualidade dos serviços educacionais disponíveis. Mesmo no caso em que a hipótese de constância no perfil socioeconômico entre gerações não possa ser considerada razoável, estratégias para controlar as variações no perfil socioeconômico seriam mais facilmente implementadas se a população alvo do Saeb fosse as gerações, ao invés de séries. Isso porque, nesse caso, nenhum problema de viés de seleção amostral estaria presente ${ }^{12}$.

O objetivo deste trabalho é avaliar o desempenho escolar entre gerações sucessivas. Restringimos a comparação à idade em que as crianças deveriam estar cursando a $4^{\text {a }}$ série do ensino fundamental, caso elas nunca tivessem sido reprovadas ou ingressado tardiamente na escola. Para enfrentar o problema de que parte das crianças de uma geração (as

10 A média (ou a mediana) não é, necessariamente, a única medida de interesse. Por exemplo, nós podemos estar preocupados em avaliar a evolução das crianças que apresentam pior desempenho (digamos, as $20 \%$ piores na distribuição).

11 Em geral o perfil socioeconômico tende a melhorar com o tempo: aumento da renda familiar per capita, elevação da escolaridade dos pais, etc. Assim, mesmo se as oportunidades educacionais fossem fixas, seria de esperar uma melhoria do desempenho escolar das crianças com o passar do tempo.

12 Existe hoje um conjunto de trabalhos que, com base nos dados do Saeb, procuram avaliar os determinantes do desempenho escolar dos alunos (Ver, por exemplo, Barbosa, Fernandes, 2000; Fontanive, Klein, 2000). Esses estudos, apesar de serem cuidadosos em relação à estrutura hierárquica dos dados do Saeb (redes, escolas, turmas e alunos), desconsideram que a amostra do Saeb é selecionada com base no próprio desempenho dos alunos. Alunos que estão na série correta tendem, mesmo condicionado no conjunto de variáveis observáveis, a serem melhores que os alunos atrasados. Tal fato impõe uma correlação entre o termo erro e os regressores, o que acaba por enviesar os coeficientes estimados. 
atrasadas e as adiantadas) não é considerada para efeitos do Saeb, calculamos, a partir dos dados das PNADs, a proporção de crianças de uma determinada geração que não estavam na série "correta" (a proporção de alunos atrasados e adiantados). Com base nessas informações (e com o auxílio de algumas hipóteses) foi possível encontrar a pontuação do aluno mediano (ou situado em algum outro décimo da distribuição de resultados) de cada uma das gerações consideradas. Quando esse procedimento é empregado, observamos que o desempenho das crianças apresentou um ligeiro crescimento entre 1995 e 1999, ao invés de uma redução.

O artigo está divido em 4 seções, além desta introdução. Na seção 2 uma análise descrevendo as pontuações médias do Saeb e a proporção de crianças fora da série considerada correta é apresentada. A seção 3 detalha a metodologia utilizada para se obter a nota do aluno mediano (ou situado em algum outro décimo da distribuição de desempenho) de uma determinada geração. Os resultados são apresentados na seção 4. Por fim, na seção 5 tecem-se os comentários finais.

\section{RESULTADOS DO SAEB E ATRASO ESCOLAR: 1995, 1997 E 1999}

A partir de 1995, o exame do Saeb tem como referencial a Teoria de Resposta ao Item (TRI), o que torna comparável as pontuações obtidas em uma disciplina entre diferentes anos ${ }^{13}$. As pontuações foram equalizadas utilizando-se a escala com média 250 e desvio padrão igual a 50, para os alunos da 8a série do ensino fundamental em 1997. Isso significa que um aluno da $4^{a}$ série, em 1999, com pontuação em matemática igual a 175 possui um desempenho em matemática que está 1,5 desvios padrão abaixo da média de desempenho em matemática dos alunos da 8a série em 1997.

A tabela 1 apresenta a média e a mediana das pontuações em matemática obtidas pelos alunos da $4^{\text {a }}$ série do ensino fundamental, enquanto que a tabela 2 apresenta as mesmas informações para língua portuguesa ${ }^{14}$.

\footnotetext{
13 Para uma discussão da TRI, ver Valle (2000).

14 Todas as médias, medianas, outros décimos da distribuição e proporções utilizadas neste trabalho foram calculadas utilizando os pesos amostrais, tanto para o Saeb como para a PNAD. As tabelas 1 e 2, para o caso das médias, apresentam resultados idênticos aos divulgados pelo MEC.
} 
Tabela 1 - Proficiência em Matemática dos Alunos da $4^{\text {a }}$ série do Ensino Fundamental

\begin{tabular}{l|ccc|ccc}
\hline \multicolumn{1}{c|}{ UF } & \multicolumn{3}{|c}{ Média } & \multicolumn{3}{c}{ Mediana } \\
\hline Norte & $\mathbf{1 9 9 5}$ & $\mathbf{1 9 9 7}$ & $\mathbf{1 9 9 9}$ & $\mathbf{1 9 9 5}$ & $\mathbf{1 9 9 7}$ & $\mathbf{1 9 9 9}$ \\
RO & $\mathbf{1 7 4 , 4 6}$ & $\mathbf{1 7 4 , 9 2}$ & $\mathbf{1 7 1 , 3 2}$ & $\mathbf{1 7 2 , 2 1}$ & $\mathbf{1 7 1 , 8 5}$ & $\mathbf{1 6 9 , 4 7}$ \\
AC & $\mathbf{1 7 5 , 1 3}$ & 180,20 & 173,51 & 168,97 & 177,41 & 172,05 \\
AM & 168,34 & 167,71 & 164,22 & 165,48 & 162,58 & 162,55 \\
RR & 179,19 & 177,79 & 175,32 & 175,07 & 171,98 & 172,52 \\
PA & 179,42 & 166,84 & 169,63 & 177,62 & 163,45 & 167,25 \\
AP & 172,88 & 173,32 & 171,16 & 172,56 & 172,13 & 169,94 \\
TO & 167,49 & 171,09 & 169,21 & 164,54 & 168,87 & 170,12 \\
\hline Nordeste & 175,66 & 177,13 & 167,54 & 173,81 & 172,40 & 164,57 \\
MA & $\mathbf{1 7 9 , 4 9}$ & $\mathbf{1 8 1 , 0 3}$ & $\mathbf{1 6 8 , 8 8}$ & $\mathbf{1 7 4 , 4 4}$ & $\mathbf{1 7 6 , 0 3}$ & $\mathbf{1 6 5 , 5 3}$ \\
PI & 174,18 & 174,91 & 167,85 & 169,94 & 169,20 & 165,01 \\
CE & 189,36 & 178,32 & 171,61 & 179,66 & 172,67 & 167,61 \\
RN & 178,31 & 184,48 & 168,35 & 174,48 & 178,66 & 165,84 \\
PB & 180,88 & 179,38 & 166,18 & 176,82 & 174,94 & 161,09 \\
PE & 179,12 & 182,41 & 174,83 & 171,99 & 182,22 & 172,33 \\
AL & 181,70 & 178,05 & 165,91 & 173,48 & 171,27 & 161,58 \\
SE & 174,79 & 173,01 & 171,67 & 171,79 & 168,12 & 168,88 \\
BA & 183,14 & 180,45 & 173,10 & 177,72 & 176,11 & 169,09 \\
\hline Sudeste & 179,33 & 185,69 & 168,67 & 175,38 & 181,43 & 165,44 \\
MG & $\mathbf{1 9 8 , 6 3}$ & $\mathbf{1 9 7 , 7 5}$ & $\mathbf{1 8 8 , 9 2}$ & $\mathbf{1 9 3 , 8 2}$ & $\mathbf{1 9 3 , 8 9}$ & $\mathbf{1 8 6 , 9 2}$ \\
ES & 203,50 & 211,38 & 188,86 & 199,22 & 215,14 & 186,34 \\
RJ & 186,02 & 181,82 & 185,46 & 180,71 & 175,91 & 181,09 \\
SP & 195,10 & 188,61 & 188,26 & 187,95 & 183,80 & 185,50 \\
\hline Sul & 198,81 & 195,67 & 189,44 & 194,38 & 190,79 & 188,35 \\
PR & $\mathbf{1 9 2 , 3 4}$ & $\mathbf{1 9 7 , 1 3}$ & $\mathbf{1 8 8 , 4 6}$ & $\mathbf{1 8 8 , 4 4}$ & $\mathbf{1 9 4 , 2 3}$ & $\mathbf{1 8 6 , 7 2}$ \\
SC & 197,99 & 199,70 & 187,10 & 197,57 & 199,49 & 185,67 \\
RS & 197,27 & 205,58 & 194,96 & 195,40 & 203,22 & 192,99 \\
Centro-Oeste & 184,85 & 190,12 & $\mathbf{1 8 6 , 3 2}$ & 179,06 & 186,29 & 184,47 \\
MS & $\mathbf{1 9 3 , 9 4}$ & $\mathbf{1 8 9 , 2 2}$ & $\mathbf{1 8 3 , 1 6}$ & $\mathbf{1 8 9 , 4 1}$ & $\mathbf{1 8 4 , 5 8}$ & $\mathbf{1 8 0 , 0 0}$ \\
MT & 192,62 & 190,30 & 182,25 & 187,19 & 186,14 & 179,24 \\
GO & 180,59 & 177,94 & 174,51 & 175,34 & 175,51 & 171,74 \\
DF & 198,84 & 193,37 & 186,85 & 195,00 & 190,33 & 185,94 \\
\hline Brasil & 197,23 & 191,04 & 185,47 & 194,88 & 184,58 & 179,62 \\
\hline & $\mathbf{1 9 0 , 6 4}$ & $\mathbf{1 9 0 , 8 0}$ & $\mathbf{1 8 1 , 0 0}$ & $\mathbf{1 8 5 , 8 4}$ & $\mathbf{1 8 5 , 8 1}$ & $\mathbf{1 7 7 , 3 9}$ \\
\hline
\end{tabular}


Tabela 2 - Proficiência em Língua Portuguesa dos Alunos da $4^{\text {a }}$ série do Ensino Fundamental

\begin{tabular}{|c|c|c|c|c|c|c|}
\hline \multirow{2}{*}{ UF } & \multicolumn{3}{|c|}{ Média } & \multicolumn{3}{|c|}{ Mediana } \\
\hline & 1995 & 1997 & 1999 & 1995 & 1997 & 1999 \\
\hline Norte & 172,60 & 172,00 & 160,21 & 172,23 & 168,83 & 156,01 \\
\hline RO & 170,63 & 173,46 & 162,53 & 169,75 & 171,59 & 160,51 \\
\hline $\mathrm{AC}$ & 168,54 & 163,25 & 154,24 & 165,21 & 159,76 & 151,57 \\
\hline $\mathbf{A M}$ & 176,09 & 176,91 & 169,02 & 175,92 & 174,26 & 163,37 \\
\hline RR & 177,46 & 161,83 & 166,55 & 177,12 & 156,95 & 162,15 \\
\hline PA & 172,68 & 171,12 & 158,22 & 172,35 & 167,43 & 153,15 \\
\hline $\mathbf{A P}$ & 165,06 & 167,82 & 164,37 & 166,70 & 162,75 & 156,13 \\
\hline TO & 171,43 & 172,78 & 151,08 & 172,08 & 170,25 & 148,11 \\
\hline Nordeste & 178,03 & 177,80 & 157,46 & 176,38 & 173,74 & 153,25 \\
\hline MA & 164,94 & 173,95 & 156,96 & 163,78 & 169,24 & 151,45 \\
\hline PI & 187,97 & 181,29 & 155,35 & 183,09 & 178,50 & 149,96 \\
\hline $\mathrm{CE}$ & 179,76 & 182,33 & 156,21 & 177,32 & 176,06 & 150,41 \\
\hline $\mathbf{R N}$ & 177,64 & 172,67 & 154,39 & 175,85 & 167,39 & 149,10 \\
\hline PB & 178,17 & 179,34 & 168,18 & 171,68 & 181,16 & 168,19 \\
\hline PE & 177,49 & 174,91 & 156,27 & 175,06 & 166,97 & 151,42 \\
\hline AL & 172,03 & 170,27 & 156,55 & 170,74 & 168,65 & 151,66 \\
\hline SE & 183,72 & 175,38 & 158,68 & 183,17 & 171,97 & 155,78 \\
\hline BA & 181,98 & 180,28 & 157,62 & 183,58 & 175,32 & 154,22 \\
\hline Sudeste & 194,83 & 193,32 & 179,78 & 193,35 & 190,12 & 175,86 \\
\hline MG & 194,80 & 208,09 & 178,70 & 192,47 & 209,31 & 173,11 \\
\hline ES & 181,08 & 176,79 & 173,77 & 178,32 & 171,81 & 169,40 \\
\hline RJ & 194,49 & 183,18 & 182,46 & 193,03 & 179,39 & 179,20 \\
\hline SP & 196,17 & 191,11 & 179,90 & 195,44 & 188,09 & 177,06 \\
\hline Sul & 191,38 & 191,10 & 179,10 & 193,30 & 188,72 & 176,48 \\
\hline PR & 197,47 & 193,43 & 179,55 & 200,91 & 191,73 & 176,87 \\
\hline SC & 189,01 & 197,05 & 180,86 & 187,83 & 195,36 & 177,67 \\
\hline RS & 186,53 & 185,65 & 177,65 & 186,27 & 183,01 & 175,28 \\
\hline Centro-Oeste & 193,40 & 183,13 & 170,54 & 192,36 & 179,70 & 166,75 \\
\hline MS & 191,03 & 184,55 & 171,80 & 189,66 & 180,84 & 168,96 \\
\hline MT & 172,30 & 171,48 & 159,37 & 170,78 & 168,51 & 154,33 \\
\hline GO & 198,63 & 186,64 & 174,10 & 196,60 & 184,44 & 171,98 \\
\hline DF & 204,51 & 186,67 & 174,09 & 203,95 & 181,10 & 166,10 \\
\hline Brasil & 188,22 & 186,46 & 170,73 & 187,18 & 181,74 & 166,63 \\
\hline
\end{tabular}


Tabela 3 - Proporção de Crianças Atrasadas/Adiantadas - $4^{\text {a }}$ Série do Ensino Fundamental como Referência

\begin{tabular}{|c|c|c|c|c|c|c|}
\hline \multirow{2}{*}{ UF } & \multicolumn{3}{|c|}{$\begin{array}{c}\text { Atrasadas ou Fora da Escola } \\
(\%)\end{array}$} & \multicolumn{3}{|c|}{ Adiantadas (\%) } \\
\hline & 1995 & 1997 & 1999 & 1995 & 1997 & 1999 \\
\hline Norte & 68,55 & 67,81 & 62,35 & 6,49 & 8,15 & 11,11 \\
\hline RO & 51,16 & 40,34 & 23,25 & 16,29 & 15,78 & 23,26 \\
\hline AC & 57,15 & 69,56 & 52,18 & 10,71 & 4,36 & 8,69 \\
\hline $\mathbf{A M}$ & 70,06 & 70,64 & 69,09 & 4,08 & 5,56 & 9,09 \\
\hline $\mathbf{R R}$ & 46,13 & 49,98 & 19,99 & 15,38 & 28,56 & 26,65 \\
\hline PA & 70,23 & 73,03 & 72,75 & 4,85 & 7,42 & 8,43 \\
\hline AP & 52,64 & 73,69 & 60,00 & 15,79 & 10,51 & 15,00 \\
\hline TO & 81,32 & 68,67 & 56,57 & 5,05 & 6,56 & 11,85 \\
\hline Nordeste & 77,87 & 76,79 & 67,73 & 5,18 & 4,84 & 7,94 \\
\hline MA & 78,69 & 80,73 & 78,61 & 4,92 & 3,65 & 3,74 \\
\hline PI & 80,54 & 78,47 & 67,83 & 5,37 & 3,47 & 7,69 \\
\hline $\mathrm{CE}$ & 78,92 & 80,62 & 64,91 & 4,28 & 5,27 & 7,97 \\
\hline RN & 55,91 & 67,43 & 57,90 & 8,66 & 5,30 & 14,03 \\
\hline PB & 78,17 & 78,57 & 60,89 & 5,63 & 4,29 & 7,82 \\
\hline PE & 74,25 & 70,75 & 65,00 & 9,12 & 7,29 & 9,51 \\
\hline $\mathbf{A L}$ & 83,18 & 80,95 & 72,38 & - & 7,62 & 6,67 \\
\hline SE & 80,00 & 65,29 & 63,03 & 6,09 & 7,44 & 5,88 \\
\hline BA & 81,00 & 77,88 & 68,83 & 3,90 & 3,34 & 8,73 \\
\hline Sudeste & 44,87 & 38,18 & 28,49 & 10,78 & 12,34 & 14,76 \\
\hline MG & 59,69 & 49,67 & 33,81 & 4,26 & 6,42 & 8,36 \\
\hline ES & 50,79 & 40,01 & 36,17 & 8,73 & 13,04 & 14,19 \\
\hline RJ & 48,08 & 47,39 & 41,05 & 13,90 & 10,62 & 14,07 \\
\hline SP & 35,36 & 29,15 & 19,73 & 13,35 & 15,87 & 18,78 \\
\hline Sul & 35,43 & 34,60 & 26,21 & 18,87 & 23,98 & 24,72 \\
\hline PR & 41,00 & 34,41 & 23,55 & 16,04 & 24,16 & 25,40 \\
\hline SC & 34,59 & 33,15 & 27,05 & 15,09 & 20,99 & 26,08 \\
\hline RS & 30,56 & 35,65 & 28,31 & 23,40 & 25,54 & 23,10 \\
\hline Centro-Oeste & 56,08 & 47,55 & 38,24 & 10,27 & 15,34 & 18,35 \\
\hline MS & 62,97 & 52,38 & 33,34 & 12,59 & 12,70 & 22,73 \\
\hline MT & 55,06 & 47,85 & 37,23 & 8,43 & 16,57 & 15,33 \\
\hline GO & 57,58 & 49,08 & 44,44 & 8,97 & 15,64 & 17,14 \\
\hline DF & 45,99 & 37,12 & 27,43 & 13,78 & 15,57 & 20,57 \\
\hline Brasil & 57,00 & 53,03 & 43,79 & 9,70 & 11,43 & 13,99 \\
\hline
\end{tabular}


Os dados dessas tabelas mostram que a média do desempenho (ou o desempenho do aluno mediano) em matemática e em língua portuguesa dos alunos da 4a série do ensino fundamental se reduziu entre 1995 e 1999. A queda se dá, fundamentalmente, entre 1997 e 1999 e ocorre em, praticamente, todos os estados. Entretanto, a magnitude da redução varia entre estados e entre regiões ${ }^{15}$. Essa queda também ocorre para os alunos situados no $6^{\circ}$ e no 7 o décimo da distribuição de habilidades ${ }^{16}$ (tabelas A1 e A2 do apêndice).

Como discutido na introdução, tal queda pode estar simplesmente refletindo uma mudança no perfil dos alunos que cursam a $4^{\text {a }}$ série do ensino fundamental, como conseqüência de uma menor taxa de repetência e evasão escolar. A tabela 3 apresenta a proporção de crianças atrasadas e adiantadas na escola, entre aquelas que "deveriam" estar cursando a $4^{\text {a }}$ série do ensino fundamental. Considerou-se as crianças que "deveriam" estar cursando a $4^{\text {a }}$ série do ensino fundamental no ano $t$, aquelas que completaram 10 anos entre julho de $t-1$ e junho de $t$. Os dados foram tabulados com base nos microdados das PNADs de 1995, 1997 e 1999.

Os dados mostram que em 1995, 57\% das crianças que "deveriam" estar cursando a $4^{\text {a }}$ série do ensino fundamental estavam em uma série inferior ou estavam fora da escola. Essa proporção se reduz para $43,79 \%$ em 1999: uma redução 13,21 pontos percentuais (23,18\%). A redução da parcela de alunos com atraso escolar ocorre em quase todos os estados, mas, novamente, a dimensão varia de estado para estado. Ela foi muito mais intensa, por exemplo, no Sudeste e no Centro-Oeste do que no Norte e Nordeste. Em São Paulo, Minas Gerais, Paraná, Mato Grosso do Sul, Rondônia e Roraima, a taxa de atraso escolar foi reduzida à metade. Uma redução no atraso escolar de tal magnitude deve ter alterado sensivelmente a distribuição de rendimento escolar dos alunos que cursaram a $4^{\text {a }}$ série em 1995 e 1999. E é essa mudança de perfil que os dados das tabelas 1 e 2 podem estar captando.

15 Destaque negativo deve ser dado ao estado de Minas Gerais, onde, entre 1997 e 1999, a pontuação média de matemática cai $10,7 \%$ e a de língua portuguesa $14,1 \%$. Uma queda de aproximadamente 0,5 desvio padrão. Para ter uma idéia de dimensão dessa redução, vale ressaltar que a diferença entre as pontuações dos alunos da $4^{\text {a }}$ série e $8^{\text {a }}$ série está em torno de 1,5 desvios padrão.

16 Uma exceção ocorre nos estados da região Nordeste para o $6^{\circ}$ décimo da distribuição de desempenho em matemática. 


\section{METODOLOGIA}

No presente trabalho três gerações foram consideradas: 1) os nascidos entre julho de 1984 e junho de 1985; 2) os nascidos entre julho de 1986 e junho de 1987; e 3) os nascidos entre julho de 1988 e junho de 1989. As crianças de cada uma das gerações foram avaliadas no ano em que elas "deveriam" estar cursando a 4 a série do ensino fundamental (1995, 1997 e 1999). Nos microdados do Saeb de 1995 todas as crianças que não pertenciam à geração um foram desconsideradas. O mesmo ocorrendo com as crianças que no Saeb de 1997 não pertenciam à geração dois e com aquelas que no Saeb de 1999 não pertenciam à geração três.

Seja $C^{*}$ o centésimo da distribuição na escala de desempenho que estamos interessados em identificar (mediana, 60 e $70^{\circ}$ centésimos da distribuição) para uma determinada geração e $C$ o centésimo da distribuição na escala de desempenho das crianças na série correta que é correspondente a $C^{*}$. Admitiu-se que todas as crianças com atraso escolar apresentam um desempenho inferior a $C^{*}$. Do mesmo modo, admitiu-se todas as crianças que se encontram adiantadas, em relação à série que deveriam cursar, possuem um desempenho superior a $C^{*}$. Com base em tais hipóteses e com as informações obtidas pela tabela 3, é possível encontrar $C$ :

$$
C=\frac{C^{*}-P_{A}}{P_{C}} \times 100
$$

onde:

$P_{\mathrm{A}}=$ Percentagem de crianças com atraso escolar

$P_{\mathrm{C}}=$ Percentagem de crianças na série correta.

Suponha, por exemplo, que estejamos interessados em identificar a pontuação do aluno mediano de uma determinada geração, sendo que, nessa geração, $20 \%$ das crianças possuem atraso escolar e 5\% estão adiantadas. Neste caso, a criança situada no $40^{\circ}$ centésimo da distribuição de habilidades das crianças que freqüentam "corretamente" a $4^{\text {a }}$ série do ensino fundamental corresponde ao aluno mediano da geração:

$$
C=40=\frac{50-20}{75} \times 100
$$

Note que tal metodologia só pode ser aplicada se a criança correspondente a $C^{*}$ encontra-se na série correta e, portanto, podemos 
estimar sua pontuação a partir da amostra do Saeb. No presente trabalho considerou-se $C^{*}=50,60$ e 70 .

\section{RESULTADOS}

Os resultados baseados no procedimento descrito na seção anterior são apresentados nas tabelas 4 e 5 . A metodologia foi aplicada para o país como um todo, para as grandes regiões e para os estados, sempre que atendida a condição $C \geq 10$. Tal restrição foi feita em virtude das pontuações localizadas nos extremos da distribuição estarem mais sujeitas a erros de medida e a outliers, o que daria pouca confiabilidade às estimativas obtidas ${ }^{17}$.

Tabela 4 - Décimos da Distribuição de Habilidades em Matemática por Geração $4{ }^{\text {a }}$ Série do Ensino Fundamental como Referência

\begin{tabular}{|c|c|c|c|c|c|c|c|c|c|}
\hline \multirow{2}{*}{ UF } & \multicolumn{3}{|c|}{ Mediana } & \multicolumn{3}{|c|}{$6^{\circ}$ Décimo } & \multicolumn{3}{|c|}{$7^{\circ}$ Décimo } \\
\hline & 1995 & 1997 & 1999 & 1995 & 1997 & 1999 & 1995 & 1997 & 1999 \\
\hline Sudeste & 157,14 & 175,56 & 184,94 & 187,70 & 203,15 & 203,32 & 217,07 & 230,88 & 224,19 \\
\hline MG & - & - & 173,97 & - & 192,68 & 194,27 & 185,05 & 227,54 & 214,53 \\
\hline ES & - & 157,61 & 172,45 & 165,69 & 179,99 & 196,19 & 186,57 & 205,99 & 217,86 \\
\hline RJ & - & - & 165,53 & 178,01 & 177,60 & 191,50 & 211,83 & 203,68 & 212,79 \\
\hline SP & 183,40 & 193,63 & 196,14 & 207,18 & 215,25 & 213,79 & 229,37 & 242,75 & 238,82 \\
\hline Sul & 174,35 & 188,08 & 194,40 & 201,57 & 217,07 & 215,86 & 223,62 & 246,73 & 242,87 \\
\hline PR & 165,25 & 191,39 & 197,29 & 199,47 & 219,16 & 221,77 & 221,87 & 248,74 & 244,85 \\
\hline SC & 178,62 & 199,52 & 198,11 & 202,39 & 224,45 & 223,29 & 218,80 & 243,60 & 253,32 \\
\hline RS & 177,52 & 179,26 & 186,31 & 201,43 & 212,73 & 210,63 & 229,68 & 245,22 & 235,04 \\
\hline Centro-Oeste & - & - & 164,88 & 161,23 & 177,00 & 188,99 & 187,70 & 210,19 & 216,60 \\
\hline MS & - & - & 177,22 & - & 160,82 & 194,17 & 176,37 & 199,96 & 227,12 \\
\hline MT & - & - & 161,81 & 158,36 & 170,62 & 178,09 & 171,07 & 195,45 & 205,10 \\
\hline GO & - & - & 155,36 & - & 177,29 & 186,10 & 188,41 & 213,59 & 205,60 \\
\hline DF & - & 175,32 & 180,69 & 191,65 & 197,83 & 213,38 & 214,25 & 227,36 & 238,69 \\
\hline Brasil & - & - & 149,94 & - & 166,21 & 178,73 & 186,38 & 201,51 & 204,81 \\
\hline
\end{tabular}

17 No caso da região Norte, a metodologia poderia ser aplicada para alguns estados em alguns anos, mas a amostra apresentou-se muito reduzida. Já para a região Nordeste, apenas Rio Grande do Norte e Sergipe poderiam ser calculados, e ainda assim apenas para o sétimo décimo da distribuição e em apenas dois anos. Deste modo, optamos por excluir os dados dessas duas regiões. 
Tabela 5 - Décimos da Distribuição de Habilidades em Língua Portuguesa por Geração - 4 ${ }^{\mathrm{a}}$ Série do Ensino Fundamental como Referência

\begin{tabular}{|c|c|c|c|c|c|c|c|c|c|}
\hline \multirow{2}{*}{ UF } & \multicolumn{3}{|c|}{ Percentil 50} & \multicolumn{3}{|c|}{ Percentil 60} & \multicolumn{3}{|c|}{ Percentil 70} \\
\hline & 1995 & 1997 & 1999 & 1995 & 1997 & 1999 & 1995 & 1997 & 1999 \\
\hline Sudeste & 150,95 & 167,95 & 177,11 & 186,21 & 196,76 & 200,08 & 211,56 & 221,79 & 226,06 \\
\hline MG & - & - & 168,76 & - & 191,47 & 190,42 & 181,11 & 222,33 & 216,07 \\
\hline ES & - & 151,29 & 157,96 & 163,87 & 178,77 & 182,84 & 187,29 & 202,89 & 203,05 \\
\hline RJ & - & - & 152,59 & 174,93 & 159,06 & 182,83 & 205,67 & 191,86 & 211,55 \\
\hline SP & 182,70 & 188,32 & 188,64 & 205,48 & 213,37 & 211,72 & 226,70 & 230,56 & 236,99 \\
\hline Sul & 169,89 & 185,34 & 183,72 & 199,72 & 210,09 & 210,30 & 229,61 & 245,87 & 239,33 \\
\hline PR & 165,76 & 189,34 & 188,72 & 198,18 & 210,71 & 213,68 & 221,66 & 253,55 & 244,14 \\
\hline SC & 176,36 & 190,89 & 186,28 & 205,75 & 212,55 & 210,59 & 224,88 & 236,93 & 251,74 \\
\hline RS & 169,18 & 175,46 & 178,23 & 198,50 & 202,20 & 204,93 & 245,86 & 248,48 & 231,52 \\
\hline Centro-Oeste & - & - & 149,38 & 146,25 & 174,23 & 177,17 & 192,39 & 199,00 & 205,64 \\
\hline MS & - & - & 169,12 & - & 166,33 & 193,58 & 171,96 & 194,71 & 230,44 \\
\hline MT & - & - & 139,27 & 127,87 & 157,67 & 162,16 & 179,81 & 185,85 & 181,53 \\
\hline GO & - & - & 137,63 & - & 176,79 & 172,54 & 196,43 & 197,91 & 199,13 \\
\hline DF & - & 168,90 & 167,57 & 180,99 & 195,45 & 195,60 & 216,33 & 226,49 & 233,04 \\
\hline Brasil & - & - & 137,93 & - & 158,06 & 169,54 & 186,92 & 195,20 & 200,08 \\
\hline
\end{tabular}

Para o país como um todo, somente para o sétimo décimo da distribuição foi possível avaliar os três anos consecutivos. Nesse caso observamos uma evolução das pontuações entre 1995 e 1999: 18,43 pontos em matemática e 13,16 pontos em língua portuguesa, correspondendo a uma evolução de $9,8 \%$ e 7,0\%, respectivamente. Essa melhora do desempenho dos alunos, entre as três gerações consideradas, pode ser observada em, praticamente, todos os casos em que a metodologia acima pode ser implementada. É interessante analisar os casos das regiões Sul e Sudeste, onde pode-se estimar, para as três gerações, a pontuação do aluno mediano, do situado no $6^{\circ}$ décimo e do situado no 70 décimo da distribuição de habilidades. Em todos os casos observamos uma melhora ${ }^{18}$. Para melhor comparar a evolução do desempenho escolar entre série e geração, as figuras 1-4 apresentam dois exemplos: mediana da distribuição de desempenho para a região Sudeste e sétimo décimo para o Brasil.

18 O único caso em que se observa uma queda na pontuação entre 1995 e 1999 é o do Rio Grande do Sul, no 7o décimo da distribuição de habilidades, em Língua Portuguesa. 

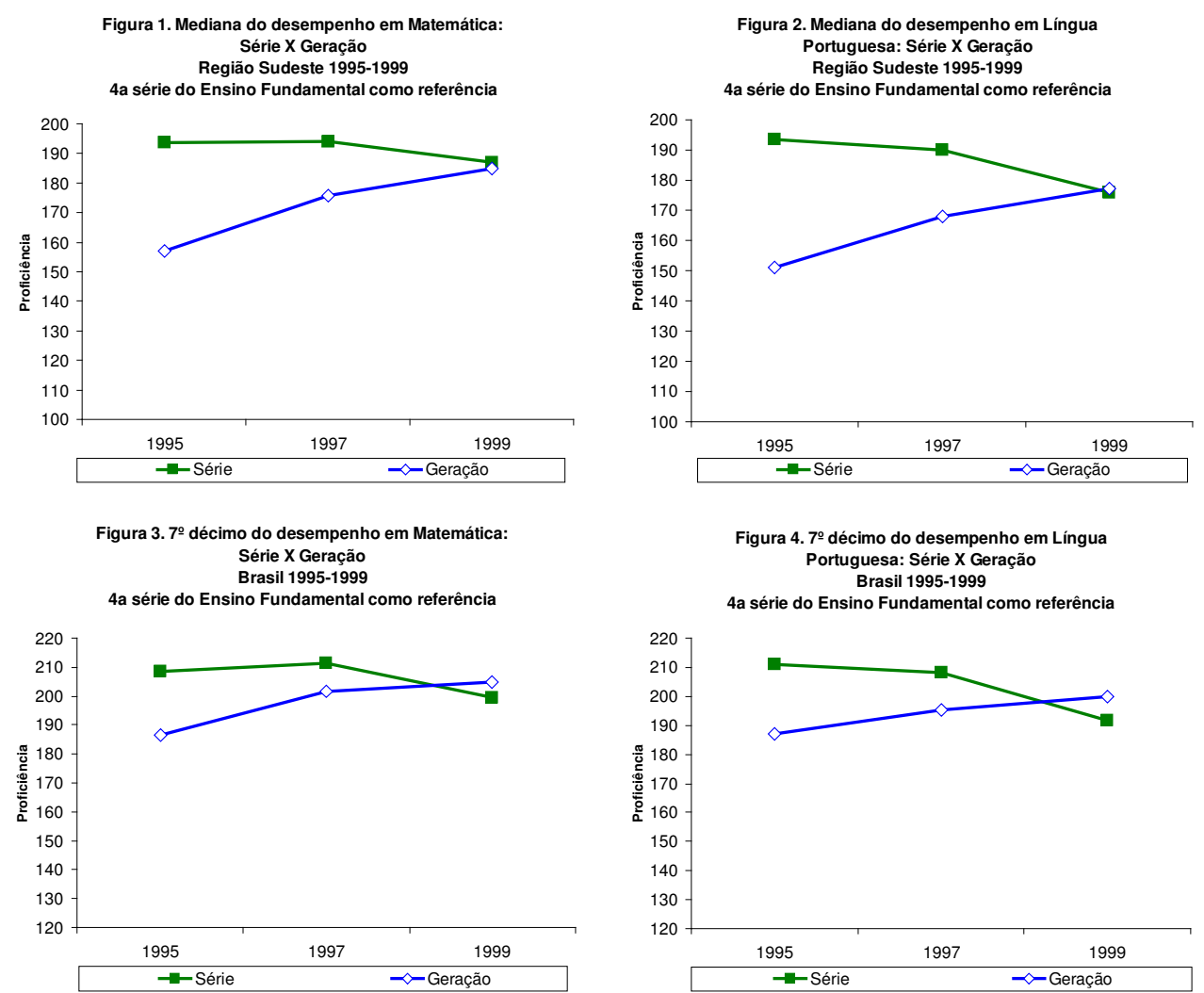

Assim, se o desempenho dos alunos que freqüentam a $4^{\text {a }}$ se reduziu no intervalo de tempo analisado, o desempenho dos alunos com idade para cursar a $4^{\text {a }}$ série se elevou, o que se constitui em uma evidência favorável à tese de que a correção no fluxo escolar, observada no período, foi a responsável pela piora no rendimento escolar detectado nas estatísticas divulgada pelo Ministério da Educação.

Tal conclusão, entretanto, merece algumas considerações. Em primeiro lugar, ela está sujeita à validade das hipóteses de que todas as crianças com atraso escolar apresentam um desempenho inferior a $C^{*}$ e de que todas as crianças que se encontram adiantadas possuem um desempenho superior a $C^{*}$. Segundo, a melhora no rendimento escolar não significa, necessariamente, que os serviços educacionais disponíveis para as gerações mais novas tenham melhorado. Uma pequena melhoria do rendimento escolar pode, muito bem, estar refletindo uma melhora do perfil socioeconômico entre as gerações, fato que não é investigado no presente trabalho. Por fim, a avaliação entre gerações deu-se com base na criança situada na parte superior da distribuição de habilidades $\left(5^{\circ}, 6^{\circ}\right.$ e $7^{\circ}$ 
décimos da distribuição). Talvez, o mais interessante seria avaliar o desempenho dos alunos situados na parte inferior da distribuição, pois são justamente esses que eram afetados pelas altas taxas de reprovação. É possível argumentar que, com bastante plausibilidade, as crianças situadas na parte inferior da distribuição de habilidades de sua geração foram aquelas mais beneficiadas pelas mudanças recentes ocorridas no sistema educacional. Isso porque um menor atraso escolar deve proporcionar a elas um melhor aprendizado. Apesar de plausível, tal argumento necessita, ainda, de uma investigação mais cuidadosa.

\section{CONSIDERAÇÕES FINAIS}

O presente trabalho procura investigar os motivos da queda no rendimento escolar apresentado pelo Saeb (1995-1999). A hipótese analisada é de que tal redução de rendimento está associada à melhora no fluxo escolar observada no período. As menores taxas de repetência e evasão teriam mudado o perfil das crianças que freqüentam uma determinada série escolar. No caso, nos restringimos a analisar a $4^{\text {a }}$ série do ensino fundamental.

A estratégia foi analisar o desempenho de gerações sucessivas: crianças com idade para freqüentar a $4^{\text {a }}$ série. Quando se avalia gerações, ao invés de série, observa-se uma pequena melhora no rendimento escolar das gerações mais novas. Tal evidência é favorável à hipótese que se buscou avaliar.

\section{REFERÊNCIAS BIBLIOGRÁFICAS}

BARBOSA, M. E. F.; FERNANDES, C. Modelo Multinível: uma aplicação a dados de Avaliação Educacional. Estudos em Avaliação Educacional, n. 22, p. 135-153, 2000.

BRANDÃO, Z.; BAETA, A. M. B.; ROCHA, A. D. C. O Estado da Arte da Pesquisa sobre Evasão e Repetência no Ensino de 10 Grau no Brasil (19711981). Revista Brasileira de Estudos Pedagógicos, v.64, n.147, p. 39-69, 1983.

CASTRO, C. M.; FLETCHER, P. R. Mitos, Estratégias e Prioridades para o Ensino de 1० Grau. Estudos em Avaliação Educacional, n.8, p. 39-56, 1993.

COLEMAN, J. S. Equality of Educational Opportunity. Washington, US. Government Printing Office, 1966. 
DEMO, P. Promoção Automática e Capitulação da Escola. Ensaio: Avaliação e Políticas Públicas em Educação, v. 6, n. 19, p. 154-190, 1998.

FLETCHER, P. R.; RIBEIRO, S. C. O Ensino de 1० Grau no Brasil Hoje. Em Aberto, v.6, n. 33, p. 1-10, 1987.

FONTANIVE, N. S.; KLEIN, R. Uma Visão sobre o Sistema de Avaliação da Educação Básica do Brasil - Saeb. Ensaio: Avaliação e Políticas Públicas em Educação, v. 8, n. 29, p. 409-442, 2000.

HANUSHEK, E. A. The Economics of Schooling: Production and Efficiency in Public Schools. Journal of Economic Literature, v. XXIV, p. 1141-1177, 1986.

MAINARDES, J. A Promoção Automática em Questão: Argumentos, Implicações e Possibilidades. Revista Brasileira de Estudos Pedagógicos, v. 79, n. 192, p. 16-29, 1998.

MINISTÉRIO DA EDUCAÇÃO. Sumário Estatístico Saeb 1999. Brasília, 1999.

MINISTÉRIO DA EDUCAÇÃO. Desempenho do Sistema Educacional Brasileiro: 1994-1999, Brasília, 2001.

NEUBAUER, R. Quem tem Medo da Progressão Continuada? Ou Melhor, A quem Interessa o Sistema de Reprovação e Exclusão Social? Acesso: Revista de Educação e Tecnologia, n. 14, 2000.

PARO, V. H. Por que os Professores Reprovam: Resultados Preliminares de uma Pesquisa. Ensaio: Avaliação e Políticas Públicas em Educação, v. 8, n. 28, p. 273-282, 2000.

RIBEIRO, S. C. A Pedagogia da Repetência. Estudos Avançados, IEA, USP, v.5, n.12, p. 7-21, 1991.

SCHIEFELBEIN, E.; WOLFF, L. Repetition and Inadequate Achievement in Latin America's Primary Schools: A Review of Magnitudes, Causes, Relationships and Strategies. Estudos em Avaliação Educacional, n. 7, p. 45-87, 1993.

SILVA, R. N.; DAVIS, C. É Proibido Repetir. Estudos em Avaliação Educacional, n.7, p. 5-44, 1993.

VALLE, R. C. Teoria da Resposta ao Item. Estudos em Avaliação Educacional, n. 21, p. 7-91, 2000.

Recebido em: maio 2003 Aprovado para publicação: setembro 2003 


\section{Apêndice}

Tabela A1 - Proficiência em Matemática dos Alunos da $4^{\text {a }}$ Série do Ensino Fundamental - $6^{\circ}$ e $7^{\circ}$ Décimos da Distribuição

\begin{tabular}{|c|c|c|c|c|c|c|}
\hline \multirow{2}{*}{ UF } & \multicolumn{3}{|c|}{$6^{0}$ Décimo } & \multicolumn{3}{|c|}{$7^{0}$ Décimo } \\
\hline & 1995 & 1997 & 1999 & 1995 & 1997 & 1999 \\
\hline Norte & 179,39 & 179,40 & 178,23 & 188,75 & 190,23 & 186,61 \\
\hline RO & 177,08 & 185,78 & 180,56 & 186,99 & 196,43 & 191,34 \\
\hline AC & 170,05 & 171,75 & 168,34 & 177,93 & 182,37 & 179,27 \\
\hline AM & 184,29 & 182,21 & 180,65 & 192,81 & 192,71 & 188,90 \\
\hline $\mathbf{R R}$ & 184,80 & 170,64 & 176,85 & 193,38 & 181,05 & 185,35 \\
\hline PA & 179,39 & 177,94 & 179,87 & 188,96 & 188,18 & 186,98 \\
\hline AP & 172,52 & 176,50 & 174,95 & 183,37 & 187,61 & 181,41 \\
\hline TO & 179,73 & 182,27 & 172,99 & 188,15 & 192,19 & 181,90 \\
\hline Nordeste & 183,35 & 185,84 & 173,91 & 194,24 & 197,34 & 184,93 \\
\hline MA & 178,65 & 178,68 & 172,43 & 189,93 & 189,64 & 183,89 \\
\hline PI & 190,79 & 184,30 & 177,11 & 202,28 & 196,44 & 187,13 \\
\hline $\mathrm{CE}$ & 181,84 & 187,42 & 174,46 & 192,56 & 200,95 & 184,05 \\
\hline RN & 187,21 & 185,10 & 170,35 & 196,21 & 195,75 & 182,24 \\
\hline PB & 181,60 & 189,93 & 182,83 & 192,46 & 200,14 & 191,02 \\
\hline$P E$ & 183,23 & 180,84 & 171,82 & 196,98 & 192,91 & 183,44 \\
\hline$A L$ & 180,01 & 177,59 & 176,88 & 189,02 & 188,63 & 186,23 \\
\hline SE & 188,80 & 186,95 & 179,42 & 199,36 & 196,50 & 189,76 \\
\hline BA & 184,26 & 192,03 & 172,57 & 195,21 & 201,99 & 182,99 \\
\hline Sudeste & 204,99 & 207,27 & 197,39 & 217,25 & 220,76 & 210,06 \\
\hline MG & 210,71 & 226,86 & 195,78 & 222,41 & 239,19 & 208,33 \\
\hline ES & 188,49 & 185,00 & 191,81 & 197,76 & 196,70 & 205,30 \\
\hline RJ & 200,08 & 196,12 & 197,76 & 213,09 & 208,98 & 207,39 \\
\hline SP & 206,22 & 204,05 & 197,81 & 217,24 & 215,36 & 211,53 \\
\hline Sul & 199,83 & 205,46 & 196,77 & 210,69 & 217,94 & 209,18 \\
\hline PR & 209,71 & 206,73 & 197,29 & 221,87 & 218,36 & 208,55 \\
\hline SC & 204,16 & 217,99 & 200,68 & 212,43 & 226,12 & 211,51 \\
\hline RS & 189,78 & 197,90 & 193,83 & 201,10 & 212,35 & 206,90 \\
\hline Centro-Oeste & 199,40 & 195,54 & 189,24 & 211,93 & 207,36 & 200,49 \\
\hline MS & 197,86 & 197,39 & 187,27 & 209,32 & 210,92 & 199,05 \\
\hline MT & 182,25 & 181,96 & 179,54 & 194,90 & 194,20 & 189,42 \\
\hline GO & 203,91 & 202,37 & 194,18 & 217,38 & 212,43 & 202,52 \\
\hline DF & 203,37 & 195,31 & 191,64 & 214,07 & 205,91 & 207,13 \\
\hline Brasil & 196,28 & 198,27 & 188,35 & 208,31 & 211,19 & 199,60 \\
\hline
\end{tabular}


Tabela A2 - Proficiência em Língua Portuguesa dos Alunos da $4^{\mathrm{a}}$ Série do Ensino Fundamental $-6^{\circ}$ e $7^{\circ}$ Décimos da Distribuição

\begin{tabular}{l|ccc|ccc}
\hline \multicolumn{1}{c|}{ UF } & \multicolumn{3}{|c|}{$\mathbf{6}^{\mathbf{0}}$ Décimo } & \multicolumn{3}{c}{$\mathbf{7}^{\mathbf{0}}$ Décimo } \\
& $\mathbf{1 9 9 5}$ & $\mathbf{1 9 9 7}$ & $\mathbf{1 9 9 9}$ & $\mathbf{1 9 9 5}$ & $\mathbf{1 9 9 7}$ & $\mathbf{1 9 9 9}$ \\
\hline Norte & $\mathbf{1 8 1 , \mathbf { 1 4 }}$ & $\mathbf{1 7 8 , 9 9}$ & $\mathbf{1 6 5 , 5 2}$ & $\mathbf{1 9 5 , \mathbf { 1 3 }}$ & $\mathbf{1 8 9 , 4 0}$ & $\mathbf{1 7 7 , 6 2}$ \\
RO & 177,49 & 181,71 & 169,96 & 187,42 & 193,66 & 179,42 \\
AC & 176,80 & 169,80 & 162,49 & 191,32 & 178,53 & 173,73 \\
AM & 186,21 & 182,42 & 175,48 & 197,42 & 193,23 & 187,93 \\
RR & 189,59 & 169,40 & 170,75 & 197,68 & 181,46 & 184,74 \\
PA & 180,93 & 177,30 & 163,20 & 199,10 & 189,13 & 175,48 \\
AP & 177,55 & 173,31 & 169,50 & 188,80 & 182,09 & 183,62 \\
TO & 181,51 & 181,63 & 156,66 & 191,27 & 189,48 & 167,11 \\
\hline Nordeste & $\mathbf{1 8 7 , 9 3}$ & $\mathbf{1 8 3 , 4 0}$ & $\mathbf{1 6 3 , 4 3}$ & $\mathbf{2 0 1 , 4 5}$ & $\mathbf{1 9 6 , 5 4}$ & $\mathbf{1 7 4 , 9 3}$ \\
MA & 175,52 & 181,79 & 160,93 & 186,82 & 192,65 & 171,68 \\
PI & 195,75 & 187,33 & 160,78 & 208,71 & 199,34 & 171,53 \\
CE & 187,12 & 188,00 & 162,39 & 198,73 & 201,43 & 174,29 \\
RN & 185,72 & 178,45 & 160,35 & 196,10 & 190,94 & 169,76 \\
PB & 184,29 & 191,15 & 175,02 & 201,20 & 200,43 & 186,54 \\
PE & 189,77 & 179,42 & 162,30 & 199,65 & 190,66 & 174,18 \\
AL & 182,49 & 178,96 & 163,30 & 197,88 & 187,99 & 172,66 \\
SE & 192,58 & 181,33 & 166,24 & 207,31 & 192,39 & 177,64 \\
BA & 194,95 & 183,93 & 162,75 & 205,96 & 200,59 & 175,56 \\
\hline Sudeste & $\mathbf{2 0 5 , 2 5}$ & $\mathbf{2 0 3 , 7 1}$ & $\mathbf{1 8 8 , 0 5}$ & $\mathbf{2 1 7 , 5 2}$ & $\mathbf{2 1 8 , 3 0}$ & $\mathbf{2 0 4 , 5 2}$ \\
MG & 204,83 & 221,26 & 186,58 & 217,81 & 236,27 & 206,09 \\
ES & 188,94 & 182,99 & 181,65 & 200,25 & 196,09 & 192,12 \\
RJ & 203,09 & 191,56 & 190,42 & 214,20 & 201,09 & 205,07 \\
SP & 207,07 & 201,88 & 188,64 & 219,95 & 215,79 & 204,45 \\
\hline Sul & $\mathbf{2 0 4 , 1 0}$ & $\mathbf{1 9 8 , 4 2}$ & $\mathbf{1 8 8 , 8 2}$ & $\mathbf{2 1 7 , 8 4}$ & $\mathbf{2 1 1 , 1 7}$ & $\mathbf{2 0 2 , 7 3}$ \\
PR & 213,30 & 200,89 & 189,85 & 223,32 & 213,54 & 202,78 \\
SC & 198,69 & 205,91 & 187,64 & 212,01 & 216,63 & 202,71 \\
RS & 198,44 & 192,17 & 188,08 & 210,20 & 204,34 & 202,14 \\
\hline Centro-Oeste & $\mathbf{2 0 3 , 5 7}$ & $\mathbf{1 9 0 , 9 4}$ & $\mathbf{1 7 7 , 5 4}$ & $\mathbf{2 1 4 , 5 5}$ & $\mathbf{2 0 0 , 6 4}$ & $\mathbf{1 9 0 , 0 5}$ \\
MS & 201,16 & 191,97 & 177,25 & 210,72 & 202,33 & 188,79 \\
MT & 181,85 & 178,94 & 165,87 & 192,89 & 188,59 & 176,16 \\
GO & 207,44 & 195,48 & 182,94 & 218,89 & 202,35 & 194,40 \\
DF & 211,35 & 192,49 & 180,14 & 224,95 & 203,25 & 200,31 \\
\hline Brasil & $\mathbf{1 9 9 , 2 7}$ & $\mathbf{1 9 4 , 2 8}$ & $\mathbf{1 7 8 , 0 5}$ & $\mathbf{2 1 1 , 2 1}$ & $\mathbf{2 0 8 , 0 7}$ & $\mathbf{1 9 1 , 6 9}$ \\
\hline & & & & & & \\
\hline
\end{tabular}


